Conference Proceedings - Long Paper

\title{
Resilience and mobility demand. Towards a redefinition of urban polycentrism. Madrid Urban Area Analysis, 1996-2014
}

\author{
Gonzalo Sánchez-Toscano ${ }^{1, *}$ and Agustín Hernández Aja ${ }^{2}$ \\ ${ }^{1}$ Urban and Land Planning Department (DUyOT), School of Architecture (ETSAM), Universidad \\ Politécnica de Madrid (UPM), Madrid, Spain. / Avenida Juan de Herrera, 4, 28040, Madrid, Spain. \\ ${ }^{2}$ Urban and Land Planning Department (DUyOT), School of Architecture (ETSAM), Universidad \\ Politécnica de Madrid (UPM), Madrid, Spain. / Avenida Juan de Herrera, 4, 28040, Madrid, Spain.
}

E-Mails: gonzalo.sancheztoscano@upm.es; agustin.hernandez@upm.es.

* Author to whom correspondence should be addressed; Tel.: +34-913366592; Fax: +34-913366534

\begin{abstract}
The mobility demand is a factor of vulnerability for urban areas in a foreseeable context of resources scarcity and fossil fuels prices rising. The perspective resilience implies the configuration of functional urban structures based on short-distance mobility flows, redefining the polycentrism as a tool for meeting the needs in close proximity. The evolution of Madrid Urban Area between 1996 and 2014 has been analysed in order to determine the mobility dependence and resilience of its different parts.
\end{abstract}

Keywords: Resilience, fossil fuels prices, mobility demand, functional urban structures, polycentricism.

\section{Introduction}

This paper focuses on the relationship between resilience and functional structure of urban areas, considering the cities dependence on mobility and fossil fuels consumption. The metropolitan expansion has increased the mobility demand for the population access to employment and other urban functions, leading urban areas to a situation of vulnerability to fossil fuels scarcity (Dodson and Sipe, 2007, 2008; Newman et al, 2014).

"Resilience" refers to the ability of urban areas to respond to multidimensional disturbances caused by different social, economic or ecological changes (Adger, 2000; Coaffee and Lee, 2016; Yamagata 
and Sharifi, 2018). Thus, the resilience perspective includes the analysis of how the functional structures of current urban areas can reduce the mobility demand, and cope with the foreseeable fossil fuels prices rising.

This work aims to contribute to a redefinition of urban areas polycentricity from the resilience perspective. Short-distance mobility flows (inner mobility) are considered the basis for more resilient functional structures, while long-distance flows (outer mobility) dependence relates to a higher vulnerability. The evolution of Madrid Urban Area functional structure between 1996 and 2014 will be assessed from this conceptual framework, identifying changes in inner and outer mobility patterns for each district in Madrid or municipality in the rest of the urban area.

The second section of the paper will develop the state of art, both referring to resilience and fossil fuels scarcity, and to functional structures and polycentricity. Methodology and case study will be respectively described in sections 3 and 4 . Results will be presented in section 5 . The discussion will be addressed in section 6 , and conclusions will be drawn in section 7 .

\section{State of the Art}

\subsection{Resilience and fossil fuels scarcity}

The introduction of the concept of resilience in urban studies has been primarily associated to the urban areas ability to face or prevent disruptive events such as natural disasters, violence or terrorism (Coaffee, 2008; Stevens et al, 2010; Muggah, 2014; Highfield et al, 2014). Nevertheless, some authors have introduced a more comprehensive approach, relating resilience to a broader range of social, economic and ecological impacts.

Adger (2000) defines "social resilience" as "the ability of groups or communities to cope with external stresses and disturbances as a result of social, political and environmental changes". Thus, resilience does not only refer to shocks or "disruptive events", but also to systemic crisis with more continuous and gradual effects ("slow burn events") (Coaffee and Lee, 2016). This wider approach to resilience in urban areas has been assumed developed in most recent scholarly literature (Méndez, 2012; Collier et al, 2013, Chelleri et al, 2015; Coaffee et al, 2018; Yamagata and Sharifi, 2018).

Some of the most relevant social, economic and environmental changes currently faced by urban areas are related to resources scarcity and, particularly, with energy and fossil fuels consumption. Authors as Dodson (and Sipe, 2007, 2008; 2014; et al, 2016) or Newman (et al, 2014; and Kenworthy, 2015) have pointed the urban areas demand for mobility and the fossil fuels prices rising associated to "peak oil" as the main factor for urban vulnerability. Hopkins (2008), Lehmann (2013), Collier et al (2013) or Sharifi and Yamagata (2016) have directly related "resilience" in urban areas to their ability to cope with energy and fossil fuels scarcity.

The concept of resilience in urban areas has also been addressed from the systems theory (Janssen et al, 2006; Ahern, 2011; Reggiani et al, 2015; Normandin and Therrien, 2016; Olazábal et al, 2018). According to this theoretical framework, resilience uses to be related to the system density (number of nodes and connections which can be activated in a given system), complexity (diversity or multiplicity of these nodes and connections), or connectivity (nodes ability to generate different, emergent or 
unexpected connections between them). Olazábal et al (2018) introduce the idea that connectivity may imply trade-offs from the resilience perspective, generating undesired negative-for-resilience effects and cause issues.

Rueda (2011) identifies urban system sustainability with the decrease in the equation $\mathrm{E} / \mathrm{nH}$, being $\mathrm{E}$ the energy consumption, $\mathrm{n}$ the number of urban entities (density), and $\mathrm{H}$ the diversity of entities (complexity). Thus, energy consumption necessarily arises as a limiting factor for the system sustainability (or "resilience"), reaching a point where neither density nor complexity might be enough to offset the increase of energy consumption.

Thus, Rueda (2011) and Olazábal et al (2018) provide some theoretical basis to consider that not all connections between nodes necessarily imply an increase of the system resilience. Given that mobility dependence is considered a factor of urban vulnerability in a context of fossil fuels scarcity (Dodson and Sipe, 2007, 2008; Newman, 2014), long-distance functional connections between the nodes of urban systems can be considered a trade-off for resilience in urban areas (Chelleri et al, 2015).

This idea may result in a reconsideration of urban system density and complexity by themselves as resilience factors, as well as in a redefinition of polycentricity by itself as the most resilient functional structure for urban areas. The perspective of resilience implies the introduction of distance as key factor for assessing the urban areas functional performance.

\subsection{Polycentricity in urban areas: Functional and morphological approaches}

The concept "polycentrism" (or "polycentricity") has been widely used in scholarly and policy literature on current urban areas functional structure, referring to the existence of several centres in a given urban area. Authors as Riguelle et al (2007) or Burger and Meijers (2012) have stressed the "vagueness", "imprecision", "loss of meaning" and "versatility" of this "fuzzy" concept, which uses to be used in a wide range of geographical scales.

"Polycentrism" has been part of different policy tools in last decades, particularly within the European Union context (EC, 1999; ESPON, 2004, 2016). These documents have underlined the importance of "polycentric development" in multiple scales (regional, national, metropolitan), assuming that European urban areas have been evolving towards more polycentric structures. However, neither conceptual definition nor evidence about the increase of "polycentrism" has been provided by this normative agenda.

Burger and Meijers (2012) classify the scholarly literature on polycentrism into "morphological" and "functional" approaches. The first relate "polycentricity" to balanced relationships between the population or employment densities in the different parts of the given urban area. The latter concern to the incoming and outcoming mobility flows (usually referred to employment) in each part of the urban area, considering "a balanced, multidirectional set of relations to be more polycentric".

Both kinds of polycentrism assessment of urban areas are based on previous definitions of "centralities" and "sub-centralities". Functional polycentricity approaches define centrality from the mobility flows attracted or emitted by each part of the urban area. So, Burger and Meijers (2012), define nodality $(\mathrm{N})$ as "the absolute importance of a centre based on internal and incoming external 
flows", and centrality (C) as "the surplus of importance of a centre based on incoming flows from other places", subtracting internal flows (I) from nodality (N). Veneri (2013) defines the flow centrality ratio (FC) as the ratio between incoming and outcoming flows in a given municipality, being a ratio higher than 1 (more incomes than outcomes) a necessary condition to be considered a centre. Zhong et al (2017) also relate the condition of centrality to the density of incoming flows in the centre.

So, these functional approaches do not consider short-distance inner flows for the definition of "centralities". According to these three definitions, a district or municipality with a high degree of internal flows would never be considered a centre, even if its nodality (relative weight in the whole system flows) is high. Likewise, urban areas functionally based on short-distance mobility would not be considered as "polycentric". On the other hand, urban areas with a high dependence on longdistance travels will achieve high ratios of incoming flows in most of its parts, being therefore considered as "polycentric". Thus, a contradiction between this definition of "polycentricity" and "resilience" can be drawn.

With regard to morphological approaches to polycentricity (Giuliano and Small, 1991; McMillen and Lester, 2003; Riguelle et al, 2007; Muñiz et al, 2008), "centrality" uses to be defined from employment densities by surface unit, usually related to the distance to Central Business District or other centres. These approaches do not consider the flows, so may not be related to short or long distance mobility.

Thus, internal flows are not considered a factor of "centrality" either in functional or morphological approaches. However, inner mobility is the only flow indicator which can be related to the classic definition of urban centres as diverse, complex and self-sufficient spaces. Centrality has also been defined as the ability of urban environments to meet the population needs in close proximity (Max Neef et al, 1986; Hernández Aja, 1997), enabling the access to the "right to the city" (Lefebvre, 1968). So, the perspective of resilience re-introduces the usefulness of urban centrality classic definitions to address the future challenges of urban areas.

\section{Methods}

\subsection{Data sources}

The study of Madrid Urban Area functional structure has been based on mobility surveys conducted by CRTM (Regional Consortium of Transport of Madrid) in 1996 and 2014. These surveys have collected, within other, data on origins, destinations and purposes of travels carried out in working days. Origins and destinations have been aggregated in districts for the city of Madrid and municipalities for the rest of the urban area.

The source does not discriminate between outward and return travels purpose, not being possible to define "attractor" and "emitter" centres. Nevertheless, it provides useful data on inner and outer travels for each district or municipality, enabling the assessment of its degree of functional interaction with the rest of the urban area and "self-sufficiency". 


\subsection{Definition of indicators}

On the basis of the described data sources, the two following indicators have been defined for 1996 and 2014 data:

- Outer Mobility Index (OMI), which represents the district or municipality degree of interaction with the rest of the urban area. It can be related to the usual definition of "centrality" in "functional polycentricity" approaches (Burger and Meijers, 2012) and it can be defined as follows:

$$
O M I=\frac{A+E}{p}
$$

In which OMI = Outer Mobility Index; $A=$ Flows attracted by the district or municipality; $E=$ Flows emitted by the district or municipality; $p=$ Population of the district or municipality in the corresponding year.

- Inner Mobility Index (IMI), which represents the district or municipality degree of resilience, related to the weight of inner travels in its functional performance. It is defined as follows:

$$
I M I=\frac{I}{p}
$$

In which IMI = Inner Mobility Index; I = Inner flows with origin and destination in the district or municipality; $\mathrm{p}=$ Population of the district or municipality in the corresponding year.

Both indicators have been defined considering only the travels with "Employment" purpose. In both cases, only flows with origin and destination inside the urban area have been considered, having been excluded the interactions with municipalities located outside Madrid Urban Area. The considered population has been the data issued by Spanish National Statistical Institute (INE) local population census in 1996 and 2004.

Besides, the degree of nodality $(\mathrm{N})$ has been calculated for each district and municipality in 1996 and 2014. According to Burger and Meijers (2012), Nodality has been defined as follows:

$$
N=\frac{A_{d}+E_{d}+I_{d}}{A_{u a}+E_{u a}+I_{u a}}
$$

In which $\mathrm{N}=$ Nodality; $A_{d}=$ Flows attracted by the district or municipality; $E_{d}=$ Flows emitted by the district or municipality; $I_{d}=$ Inner flows in the district or municipality; $A_{u a}=$ Flows attracted by all districts and municipalities in the urban area; $E_{u a}=$ Flows emitted by all districts and municipalities in the urban area; $I_{u a}=$ Inner flows in all districts and municipalities in the urban area.

Districts and municipalities with $\mathrm{N} \geq 1 \%$ have been considered high nodality areas within Madrid Urban Area (according to methodology used by Muñiz et al, 2008). 


\subsection{Cross-tab analysis}

Once defined OMI and IMI, districts and municipalities functional performance in 1996 and 2014 has been classified according to their results in these two indicators. In both cases, classification has been carried out with reference to the whole Urban Area average scores.

OMI has been used to define the degree of functional interaction between the district or municipality and the rest of the Urban Area. Districts and municipalities with higher OMI than Urban Area average score have been considered Interacting, whereas the ones with lower OMI than average score have been considered Not Interacting.

IMI has defined the degree of the district or municipality functional resilience. Districts and municipalities with higher IMI than Urban Area average score have been considered Resilient, whereas the ones with lower IMI than average score have been considered Not Resilient.

The cross-tab analysis of both classifications has led to four potential functional categories of districts and municipalities: Interacting Resilient (I-R), Interacting Not Resilient (I-NR); Not Interacting Resilient (NI-R), and Not Interacting Not Resilient (NI-NR).

\section{Case study description}

The case study area has been Madrid Urban Area, according to Ayuntamiento de Madrid (2014) delimitation referred to inner (Consolidated Urban Area) and outer (Expanding Urban Area) rings. An adjustment of the outer ring delimitation has been made according to data availability. A total of 50 municipalities have been studied, having disaggregated Madrid data into 21 districts. Thus, a total of 70 territorial entities have been analysed.

The period under study (1996-2014) relates to the final stage of Madrid Urban Area expansion process, from 4.819 .554 inhabitants in 1996 to 6.041 .027 in $2014(+25,34 \%)$. The population increase has been more relevant in outer ring (from 583.975 to 1.119 .278 inhabitants, $+91,67 \%$ ), than in inner ring (from 1.368.729 to $1.756 .514,+28,33 \%$ ) and Madrid municipality (from 2.866.850 to 3.165.235, $+10,41 \%)$.

Results have been shown in charts according to this geographical classification: Madrid Central Almond (Central Business District), peripheral districts of Madrid, inner ring and outer ring. All peripheries have been also divided through the North-East/ South-West line which has historically defined the social division of Madrid Urban Area, corresponding North-West to upper classes and South-East to working classes (Gómez Giménez, 2017).

\section{Results}

\subsection{Evolution 1996-2014. General trends in Madrid Urban Area.}

Figure 1 shows the results of OMI and IMI cross-tab analysis for 1996 and 2014. Madrid Urban Area average scores for both indicators have been drawn as dotted lines, delimiting the four categories above defined. 
Figure 1. Results of cross-tab analysis for 1996 and 2014.

\section{A. Results 1996}

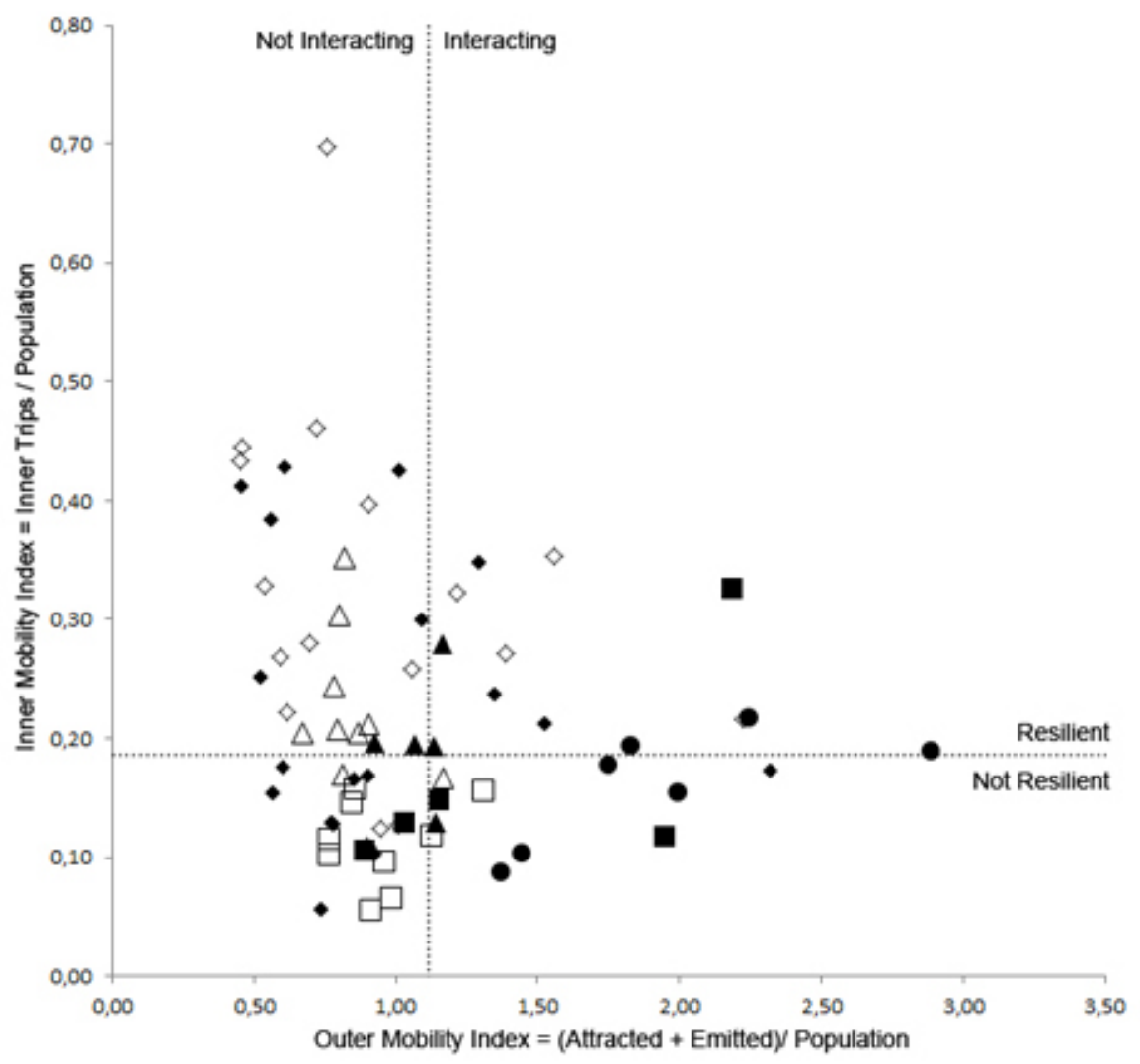

B. Results 2014

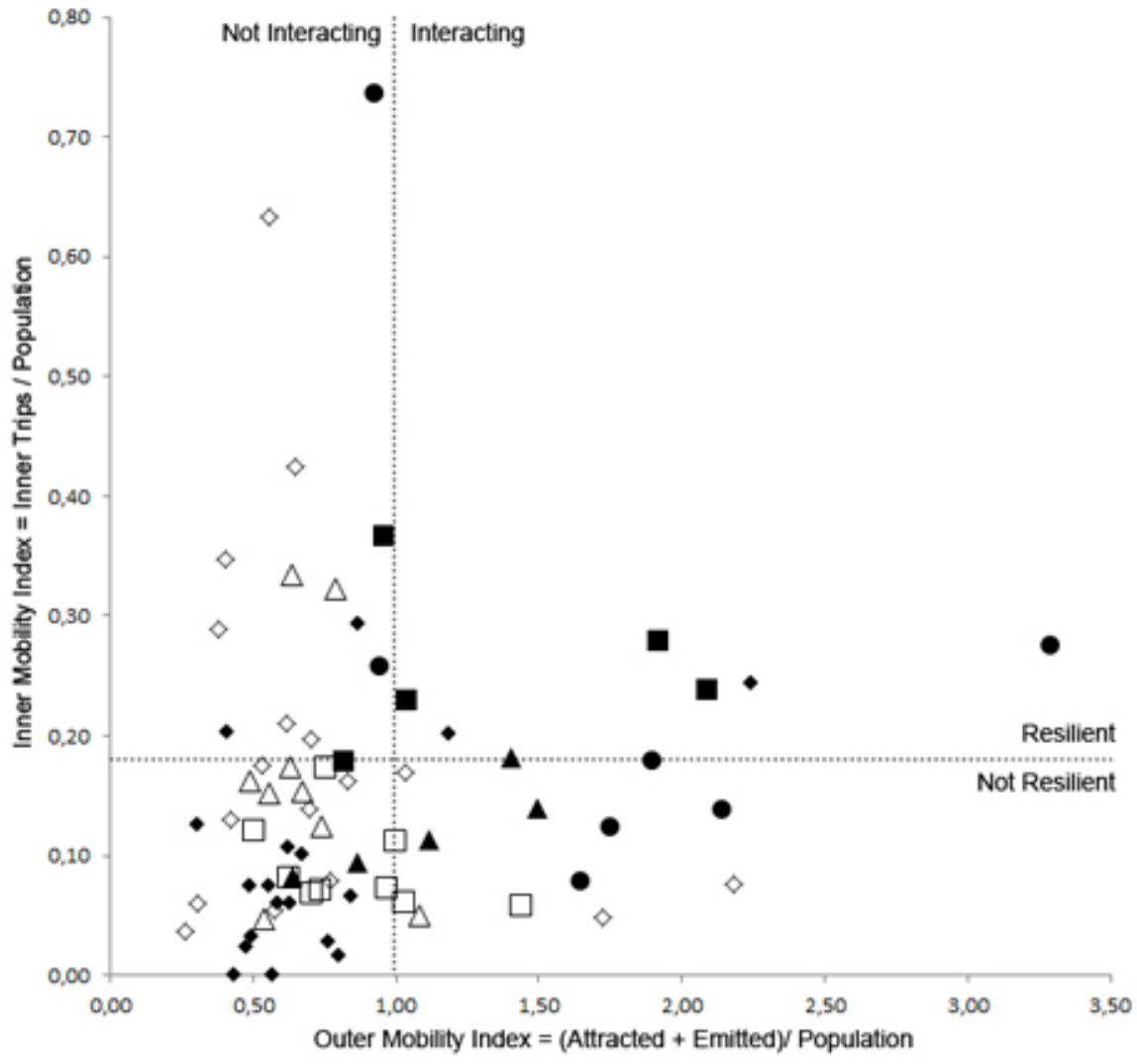

\section{Legend}

- Madrid Central Almond

Peripheral Madrid- North

$\square$ Peripheral Madrid- South

A Inner Ring- North

$\Delta$ Inner Ring- South

- Outer Ring- North

$\diamond$ Outer Ring- South

Prepared by the authors on the basis of mobility surveys conducted by CRTM (Regional Consortium of Transport of Madrid) in 1996 and 2014. 
As seen in the graph, Madrid Central Almond districts and northern districts and municipalities (corresponding to upper classes) tend to get high scores in Outer Mobility Index, being more interacting with the Urban Area flow system, associated in scholarly literature to "functional polycentrism" (Burger and Meijers, 2012). On the other hand, southern districts and municipalities (inhabited by working classes) tend to get low scores in outer mobility, not interacting with the rest of the Urban Area.

Continuing with the outer mobility analysis, the graph shows how Madrid Urban Area average score has decreased between 1996 and 2014. This process has supposed a polarization in the degree of interaction for the different parts of the urban area. Some central and northern districts of Madrid municipality have kept their medium or high levels of interaction, and some northern inner ring municipalities have increased their score. On the other hand, most of outer ring peripheries and southern Madrid districts or inner ring municipalities scores have decreased.

With regard to Inner Mobility Index, much more relevant differences between 1996 and 2014 results can be drawn. In 1996, most of southern municipalities in the inner and outer ring had a resilient position, with a high score related to inner flows. In 2014, most of them have significantly reduced their inner mobility score, which implies a loss of resilience. Northern and southern outer ring municipalities show the same trend. Most of southern Madrid districts, due to their more central position and their ability to interact with other districts, already used to have low inner mobility scores in 1996, that nonetheless have also decreased in 2014.

Central and northern Madrid districts present the opposite trend in Inner Mobility Index results. These areas used to have in 1996 lower inner mobility scores than the southern districts and municipalities and than the whole Urban Area. However, in 2014 some central and most of northern districts have considerably increased their scores. Inner ring northern municipalities have kept in 2014 similar results to the ones scored in 1996, around or below Urban Area average.

\subsection{Results territorialization in Madrid Urban Area}

Figure 2 shows the spatial layout of the above described results in Madrid Urban Area for 1996 and 2014. High nodality areas, representing more than $1 \%$ of total flows emitted and attracted in the urban area, are represented in solid hatching, while low nodality districts and municipalities have been pictured in dotted hatching.

The figure represents how the functional configuration of Madrid Urban Area in the last two decades has led the southern inner ring municipalities from a resilient situation to a not resilient one, that has not even supposed a higher interaction with the rest of the urban area. The working-class corridor of southern and eastern Madrid Urban Area has nine high nodality municipalities. In 1996, eight of them had a Not Interacting Resilient (NI-R) situation, with a significant importance of inner travels, while only one has been classified as Not Interacting Not Resilient (NI-NR). In 2014, seven of these municipalities have scored as NI-NR, with a low degree of both interaction and self-sufficiency, while only two remain as NI-R. 
Figure 2. Territorialization of results. 1996 and 2014.

A. Results 1996

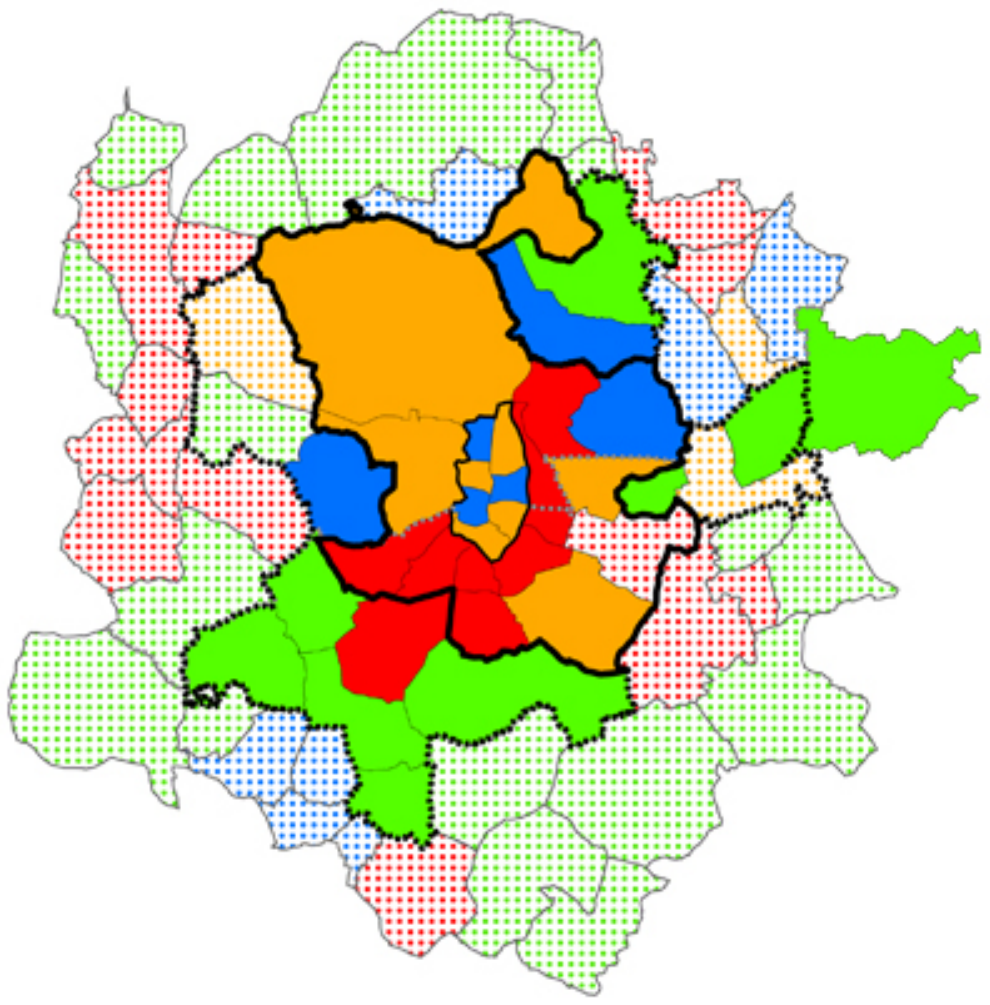

B. Results 2014

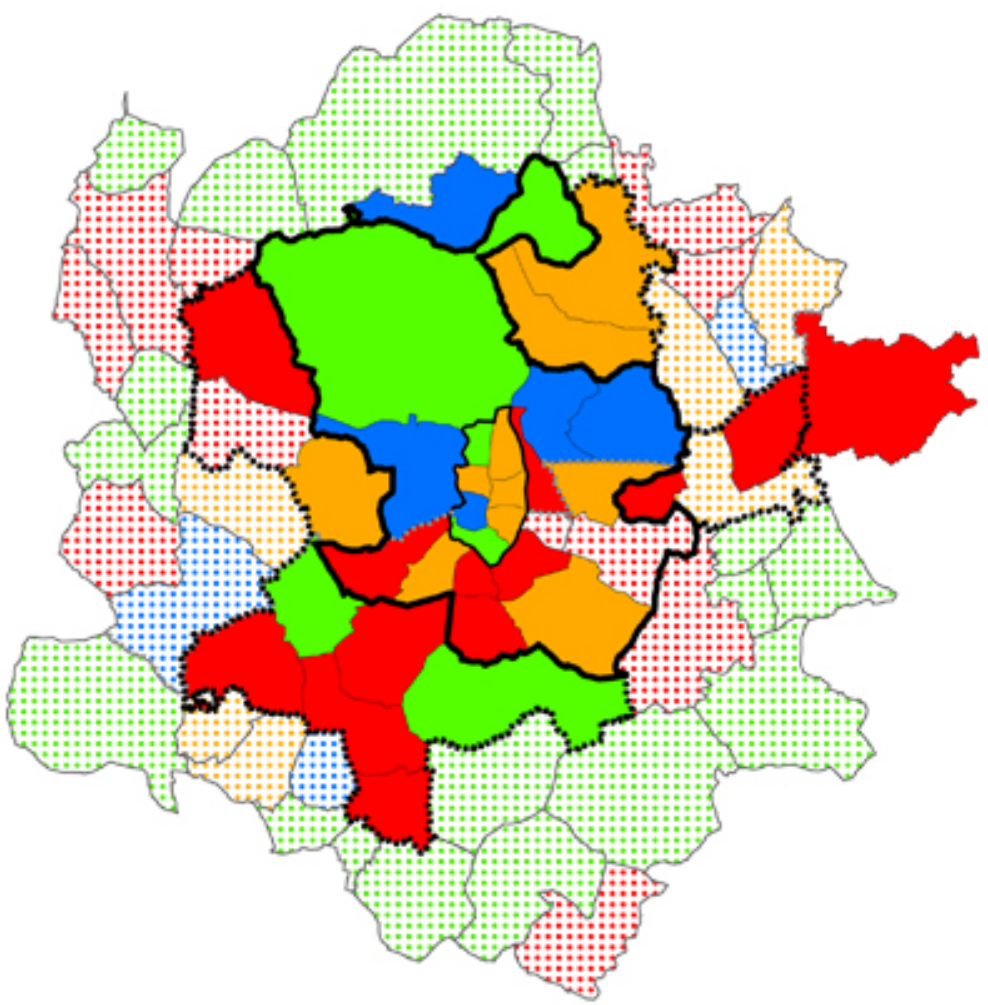

Legend

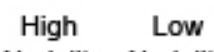

Nodality Nodality

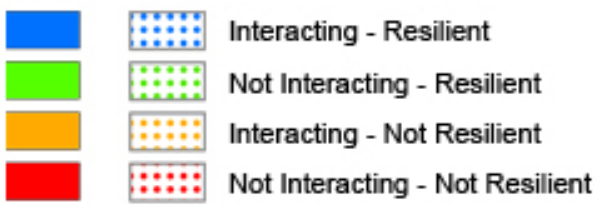

- Madrid Central Almond

- Madrid Municipality

Madrid Urban Area Inner Ring

Madrid socio-economic line

Prepared by the authors on the basis of mobility surveys conducted by CRTM (Regional Consortium of Transport of Madrid) in 1996 and 2014. 
With regard to Madrid municipality, three of five northern districts have led to a more resilient position, moving from I-NR to I-R situation, from I-NR to NI-R or even from NI-NR to I-R. In Madrid Central Almond, the two districts with lowest average income (Tetuán and Arganzuela) have moved from high interaction positions in 1996 to low interaction ones in 2014, reinforcing their selfsufficiency and being classified as NI-R. The rest of central districts remain in highly interacting situations (I-NR or I-R). Most of southern districts have been classified as NI-NR in both 1996 and 2014, with some of them getting a higher level of interaction due to their relationship with Madrid second ring road M-40.

\section{Discussion}

The significant expansion of Madrid during the period 1996-2014, corresponding to the growth and collapse of Spanish real state bubble, has changed the functional structure of Madrid Urban Area. This process has developed in a context of supposed decentralization of employment and economic activities, leading towards a more polycentric functional structure.

However, in the case of Madrid Urban Area, this process towards "functional polycentrism" (Burger and Meijers, 2012) has not been translated into a more resilient functional structure. Mobility demand has not significantly decreased and large parts of the urban area have lost their previous selfsufficiency for labour mobility, based on short-distance and inner travels within municipalities.

Besides, the process towards "functional polycentrism" has accentuated the historical socioeconomic imbalance between the North and the South of Madrid Urban Area. The southern inner ring municipalities which configure the historical working class corridor have been left out of the configuration of "polycentric" functional structure. None of them gets scores of interaction with the rest of the Urban Area higher than the average score. On the contrary, most of them have lost their ability to provide employment to their inhabitants in their own municipality. This previous situation enabled a more resilient and less mobility-demanding functional performance in these municipalities, which has led to their functional isolation and loss of self-sufficiency.

This functional configuration has not been oblivious to the evolution of the Spanish and Madrid Urban Area economy itself. The larger municipalities in the south of Madrid have been historically associated to industrial activities. The process of deindustrialization and financialization of Spanish economy since the eighties has supposed the progressive decrease of economic activity and employment opportunities in these municipalities, which have not been replaced by other labour sectors and tertiary activities.

On the other hand, financialization has strengthened both the resilience and the functional role of northern Madrid districts, historically associated to upper classes. New tertiary activities have developed in these areas, close to the second ring road of Madrid (M40), maintaining or increasing their degree of interaction with the rest of the urban area. Meanwhile, new urban developments for middle and upper classes in these districts have enabled these tertiary sector workers to move to a closer area from their workplace, increasing simultaneously the resilience of these parts of the urban area. 
With regard to the most central part of the urban area, Madrid Central Almond, the results show that the supposed decentralization associated to the configuration of a more "polycentric" structure has not taken place. The districts that form the traditional Central Business District (CBD) of Madrid Urban Area (Centro, Salamanca, Chamberí, Chamartín and Retiro) remain within the most interacting with the rest of the urban area, having decreased their inner mobility. Only the lowest average income districts (Tetuán and Arganzuela) have decreased the high degree of outer mobility associated to their central position, increasing meanwhile their resilience and inner mobility.

\section{Conclusions}

The academic debate on urban resilience may not avoid the vulnerability of functional structures based on mobility demand for the access to employment and other urban functions. The resilience to resources scarcity and fossil fuels prices rising introduces a new perspective in the urban areas functional analysis which leads to a redefinition of "polycentrism". Resilient functional structures will be the ones enabling the population to access to primary urban functions in proximity, and being based on short-distance and inner travels.

The study of the evolution of Madrid Urban Area during the expansion carried out between 1996 and 2014 has shown that functional structure is not leading to a more resilient configuration. On the contrary, this process has reduced the resilience and self-sufficiency of historically industrial peripheries, which have neither increased their functional interaction with the rest of the urban area.

Thus, urban analysis and planning policies may incorporate the resilience perspective to achieve less mobility-demanding urban areas. This approach implies considering polycentrism as a tool for meeting the needs in closer proximity, and not for increasing the mobility dependence. Resilient urban structures may be based in balanced social, functional and economic distributions within the different parts of the urban area, avoiding situations of overlapped vulnerabilities.

\section{Acknowledgments}

The research of this paper was done within the project "Resiliencia funcional de las áreas urbanas. El caso del Área Urbana de Madrid”, BIA2015-64782-R, funded by the Ministerio de Economía y Competitividad through the program Programa estatal de $I+D+i$ orientada a los retos de la sociedad. The authors would like to thank to Ana Sanz Fernández and Ana Díez Bermejo, members of the above mentioned project and who have contributed to the development of the theoretical basis for a comprehensive and critical perspective on resilience.

\section{Conflict of Interest}

The authors declare no conflict of interest.

\section{References and Notes}

Adger, W. Neil. 2005. «Social and ecological resilience: are they related?» Science 309 (5373): 1036-39. doi:10.1191/030913200701540465. 
- $\quad$ Ahern, Jack. 2011. «From fail-safe to safe-to-fail: Sustainability and resilience in the new urban world». Landscape and Urban Planning $100 \quad$ (4). Elsevier B.V.: 341-43. doi:10.1016/j.landurbplan.2011.02.021.

Ayuntamiento de Madrid. 2014. «Dimensión territorial y socioeconómica de la región metropolitana de Madrid» Barómetro de Economía de la ciudad de Madrid 39: 104-130.

Burger, Martijn, and Evert Meijers. 2012. «Form follows function? linking morphological and functional polycentricity». Urban Studies 49 (5): 1127-49. doi:10.1177/0042098011407095.

- Chelleri, Lorenzo, James J Waters, Marta Olazabal, and Guido Minucci. 2015. «Resilience trade-offs addressing multiple scales and temporal aspects of urban resilience», n. ${ }^{\circ}$ 3: 1-18.

- $\quad$ Coaffee, Jon. 2008. «Risk, resilience, and environmentally sustainable cities». Energy Policy 36 (12): 4633-38. doi:10.1016/j.enpol.2008.09.048.

- Coaffee, Jon, and Peter Lee. 2016. Urban Resilience. Planning for Risk, Crisis and Uncertainty. Red Globe Press. ISBN: 978-1137288837

- $\quad$ Coaffee, Jon, Marie Christine Therrien, Lorenzo Chelleri, Daniel Henstra, Daniel P. Aldrich, Carrie L. Mitchell, Sasha Tsenkova, and Éric Rigaud. 2018. «Urban resilience implementation: A policy challenge and research agenda for the 21 st century». Journal of Contingencies and Crisis Management 26 (3): 403-10. doi:10.1111/1468-5973.12233.

- Collier, Marcus J., Zorica Nedović-Budić, Jeroen Aerts, Stuart Connop, Dermot Foley, Karen Foley, Darryl Newport, Siobhán McQuaid, Aleksander Slaev, and Peter Verburg. 2013. «Transitioning to resilience and sustainability in urban communities». Cities 32. doi:10.1016/j.cities.2013.03.010.

- Dodson, Jago, and Neil Sipe. 2007. «Oil vulnerability in the Australian City: Assessing socioeconomic risks from higher urban fuel prices». Urban Studies 44 (1): 37-62. doi:10.1080/00420980601023810.

- Dodson, Jago, and Neil Sipe. 2008. «Shocking the suburbs: Urban location, homeownership and oil vulnerability in the Australian City». Housing Studies 23 (3): 377-401. doi:10.1080/02673030802015619.

- Dodson, Jago. 2014. «Suburbia under an Energy Transition: A Socio-technical Perspective». Urban Studies 51 (7): 1487-1505. doi:10.1177/0042098013500083.

- $\quad$ Dodson, Jago, Neil Sipe, and Anitra Nelson. 2016. Planning after Petroleum. Preparing Cities for the Age beyond Oil. Routledge. ISBN: 978-0415504577.

- $\quad$ European Commission (EC). 1999. European Spatial Development Perspective: Towards Balanced and Sustainable Development of the Territory of the European Union. European Planning Studies. Vol. 13. doi:10.2747/0272-3638.28.7.702.

- $\quad$ European Observation Network for Territorial Development and Cohesion (ESPON). 2004. Potentials for polycentric development in Europe. Stockholm/Luxembourg: Nordregio/ESPON. 
- $\quad$ European Observation Network for Territorial Development and Cohesion (ESPON). 2016. «Polycentric Territorial Structures and Territorial Cooperation». ESPON Policy Brief, 6. Luxembourg: ESPON.

- Giuliano, Genevieve, and Kenneth A. Small. 1991. «Subcenters in the Los Angeles region». Regional Science and Urban Economics 21 (2): 163-82. doi:10.1016/0166-0462(91)90032-I.

Gómez Giménez, José Manuel. 2017. «Madrid functional urban area (1991-2011). A multicriterial proposal on demarcation and characterisation. Methodology and results». Territorios en Formación 11:3-23.

- $\quad$ Hernández Aja, Agustín. 1997. La ciudad de los ciudadanos. Madrid: Ministerio de Fomento.

- Highfield, Wesley E., Walter Gillis Peacock, and Shannon Van Zandt. 2014. «Mitigation Planning: Why Hazard Exposure, Structural Vulnerability, and Social Vulnerability Matter». Journal of Planning Education and Research 34 (3): 287-300. doi:10.1177/0739456X14531828.

- $\quad$ Hopkins, Rob. 2008. The Transition Handbook. From Oil Dependency to Local Resilience. ISBN: 978-1900322188.

- Janssen, Marco, John M Anderies, Thomas Elmqvist, and Ryan Rj Mcallister. 2015. «Toward a Network Perspective of the Study of Resilience in Social-Ecological Systems». Ecology and Society $11(1): 15$.

- $\quad$ Lefebvre, Henri. 2008. Le droit à la ville. Paris: Éditions Anthropos.

- $\quad$ Lehmann, Steffen. 2013. «Low-to-no carbon city: Lessons from western urban projects for the rapid transformation of Shanghai». Habitat International 37. Elsevier Ltd: 61-69. doi:10.1016/j.habitatint.2011.12.014.

- Max Neef, Manfred, Antonio Elizalde, and Martín Hopenhayn. 1986. Desarrollo a Escala Humana: una Opción para el Futuro. Santiago: CEPAUR.

- McMillen, Daniel P., and T. William Lester. 2003. «Evolving subcenters: Employment and population densities in Chicago, 1970-2020». Journal of Housing Economics 12 (1): 60-81. doi:10.1016/S1051-1377(03)00005-6.

- Méndez, Ricardo. 2012. «Ciudades y metáforas: sobre el concepto de resiliencia urbana». Ciudad y territorio. Estudios Territoriales. XLIV (172): 215-32.

- Muggah, Robert. 2014. «Deconstructing the fragile city: exploring insecurity, violence and resilience». Environment and Urbanization 26 (2): 345-58. doi:10.1177/0956247814533627.

- Muñiz, Ivan, Àngel Miquel Garcia-López, and Anna Galindo. 2008. «The effect of employment sub-centres on population density in Barcelona». Urban Studies 45 (3): 627-49. doi:10.1177/0042098007087338. 
- $\quad$ Newman, Peter, Timothy Beatley, and Heather Boyer. 2014. Resilient Cities. Responding to Peak Oil and Climate Change. Island Press. ISBN: 978-1597264990.

- $\quad$ Newman, Peter, and Jeffrey Kenworthy. 2015. The End of Automobile Dependence. How Cities are Moving Beyond Car-Based Planning. Island Press. ISBN: 978-1610914635.

- Normandin, Julie Maude, and Marie Christine Therrien. 2016. «Resilience Factors Reconciled with Complexity: The Dynamics of Order and Disorder». Journal of Contingencies and Crisis Management 24 (2): 107-18. doi:10.1111/1468-5973.12107.

- Olazábal, Marta, Lorenzo Chelleri, and Ayyoob Sharifi. 2018. «Is Connectivity a Desirable Property in Urban Resilience Assessments?». Chapter in Yamagata and Sharifi (2018)

- $\quad$ Reggiani, Aura, Peter Nijkamp, and Diego Lanzi. 2015. «Transport resilience and vulnerability: The role of connectivity». Transportation Research Part A: Policy and Practice 81. Elsevier Ltd: 4-15. doi:10.1016/j.tra.2014.12.012.

- Riguelle, François, Isabelle Thomas, and Ann Verhetsel. 2007. «Measuring urban polycentrism: A European case study and its implications». Journal of Economic Geography 7 (2): 193-215. doi:10.1093/jeg/lb1025.

- $\quad$ Rueda, Salvador. 2011. «El urbanismo ecológico». Urban-e, 2.

- Sharifi, Ayyoob, and Yoshiki Yamagata. 2016. «Principles and criteria for assessing urban energy resilience: A literature review». Renewable and Sustainable Energy Reviews 60: 1654-77. doi:10.1016/j.rser.2016.03.028.

- Stevens, Mark R., Philip R. Berke, and Yan Song. 2010. «Creating disaster-resilient communities: Evaluating the promise and performance of new urbanism». Landscape and Urban Planning 94 (2): 105-15. doi:10.1016/j.landurbplan.2009.08.004.

- Veneri, Paolo. 2013. «The identification of sub-centres in two Italian metropolitan areas: A functional approach». Cities 31: 177-85. doi:10.1016/j.cities.2012.04.006.

- Yamagata, Yoshiki, and Ayyoob Sharifi. 2018. Resilience- Oriented Urban Planning. Theoretical and Empirical Insights. Springer. ISBN: 978-3319757971

- Zhong, Chen, Markus Schläpfer, Stefan Müller Arisona, Michael Batty, Carlo Ratti, and Gerhard Schmitt. 2017. «Revealing centrality in the spatial structure of cities from human activity patterns». Urban Studies 54 (2): 437-55. doi:10.1177/0042098015601599.

(C) 2018 by the authors; licensee MDPI and IFoU, This article is an open access article distributed under the terms and conditions of the Creative Commons Attribution license. 